\title{
Práticas de lazer de idosos institucionalizados
}

\author{
Giselle Alves de Moura* \\ Luciana Karine de Souza**
}

\begin{abstract}
Resumo: O estudo relata as experiências das práticas de lazer em idosos residentes em instituições de longa permanência filantrópicas conveniadas com a Prefeitura de Belo Horizonte. Trata-se de uma pesquisa predominantemente qualitativa que se insere no campo interdisciplinar dos estudos do lazer. Foram entrevistados 47 idosos (70\% mulheres), com média de idade de 80 anos. As práticas mais citadas foram religiosas, relações interpessoais, ginástica, assistir televisão e práticas manuais e artesanais. Os resultados são discutidos com base na literatura e são traçadas recomendações para o profissional que pretende promover lazer ao idoso institucionalizado.
\end{abstract}

Palavras-chave: Atividades de lazer. Idoso. Instituição de longa permanência para idosos.

\section{INTRODUÇÃo}

O presente estudo relata as experiências das práticas de lazer em idosos residentes em instituições de longa permanência filantrópicas conveniadas com a Prefeitura de Belo Horizonte (PBH), Minas Gerais. Trata-se de uma pesquisa que se insere no campo interdisciplinar dos estudos do lazer. O texto inicia com um curto traçado sobre o papel do trabalho na vida humana até a experiência de lazer no tempo disponível do idoso após a aposentadoria. Traz-se uma definição abrangente de lazer, na interface com a discussão sobre o tempo livre e o tempo disponível, com posteriores considerações acerca das experiências de lazer dos residentes em

\footnotetext{
'Servidora da ?Prefeitura Municipal de Belo Horizonte, Mestranda do PPG Estudos de Lazer, Universidade Federal de Minas Gerais, Belo Horizonte, MG. E-mail: giselleamoura@gmail.com

"Professora do PPG Estudos de Lazer, Universidade Federal de Minas Gerais, Belo Horizonte, MG. E-mail: lucianak@fafich.ufmg.br
} 
Instituições de Longa Permanência para Idosos (ILPIs). Em seguida, apresenta-se o estudo empírico desenvolvido, cujo objetivo foi investigar as experiências atuais das práticas de lazer em moradores de ILPIs filantrópicas conveniadas com a PBH.

A valorização humana do trabalho o transforma em principal fonte de significados na vida das pessoas, especialmente pelo senso de utilidade. Ao mesmo tempo necessário à sobrevivência e causador de sofrimento, o trabalho pode proporcionar experiências, satisfação de necessidades materiais e afetivas e o desenvolvimento de habilidades (D'ALENCAR; CAMPOS, 2006; SOARES et al., 2007). Na velhice o trabalho confere uma sensação de "estar integrado na sociedade" (DOLL, 2007, p.11).

É também no contraponto ao tempo de trabalho que se encontra a discussão sobre o tempo livre e o tempo de lazer. A denominação de tempo livre adveio da natureza cronológica e atingiu seu apogeu pós-revolução industrial (AQUINO; MARTINS, 2007). Em uma perspectiva sociológica, Marcellino (1996) considera que o lazer ligado ao aspecto tempo envolve liberação das obrigações profissionais e também familiares, sociais e religiosas. Com esse entendimento, nas relações sociais nenhum tempo está livre das normas de conduta social; por isso sugere o termo "tempo disponível" (MARCELLINO, 1996).

No decorrer da vida se percebe que a quantidade de tempo livre é maior na infância e adolescência, diminuindo na fase adulta e aumentando com a aposentadoria. Muitas vezes este tempo não é valorizado pelos aposentados, acostumados no ritmo da produção. Logo, faz-se necessário uma preparação educativa para usufruírem deste tempo (MORAGAS, 1997; FERRARI, 2007), reelaborando a própria autonomia, possibilitando a escolha ou a renúncia de práticas de lazer conforme suas necessidades e interesses (RODRIGUES, 2002).

O lazer inclui a fruição de diversas manifestações culturais como o jogo, a brincadeira, a festa, o passeio, a viagem, o esporte e diversas formas de arte. Gomes (2003, 2004) entende lazer como "uma dimensão da cultura constituída por meio da vivência lúdica de 
manifestações culturais em um tempo/espaço conquistado pelo sujeito ou grupo social, estabelecendo relações dialéticas com as necessidades, os deveres e as obrigações, especialmente com o trabalho produtivo".

O lazer traz contribuições importantes para a inserção do idoso no ambiente social. Diante do novo quadro de aumento da população idosa brasileira, é preciso conscientizar sobre as mudanças necessárias para o bem-estar dessa população, inclusive os residentes de moradias coletivas - instituições de longa permanência para idosos. Para isto é preciso desconstruir a ideia de caridade de outros tempos, e entender estes locais como instituições prestadoras de serviço diante da demanda atual de atendimento ao idoso.

As ILPIs são também conhecidas como abrigo, lar, asilo, casa de repouso, clínica geriátrica e ancionato. $\mathrm{O}$ uso dos termos casa e asilo são distintos nas Normas de Funcionamento de Serviços de Atendimento ao Idoso no Brasil de 2005. Enquanto casa está relacionada a domicílio, a palavra asilo traz a ideia de refúgio, e abrigo refere-se a proteção (FALEIROS; MORANO, 2009). Já a denominação clínica geriátrica deve-se ao fato de que muitas demonstram fortes traços de ambientes médicos. O trabalho diário está centrado, na maioria das vezes, em atender as necessidades básicas diárias dos idosos (AGICH, 2008). No entanto, a denominação ILPI somente é oficializada como norma federal a partir da Resolução 283/2005 da Agência Nacional de Vigilância Sanitária (ANVISA). Para Camarano e Kanso (2010) a ILPI não é um estabelecimento de cunho clínico ou terapêutico, e sim uma residência coletiva que atende idosos independentes ou idosos com dificuldades para desempenhar atividades de vida diária.

Atualmente os novos residentes das ILPIs apresentam características e necessidades diferenciadas de outras épocas. Há idosos que buscam uma ILPI para morar por opção própria, outros para manter a independência funcional mesmo diante dos problemas de saúde. Há aqueles que querem evitar gerar custos para os familiares; outros desejam uma vida social mais ativa convivendo com pessoas da mesma faixa etária. 
A rotina oferece pouco ao tempo disponível do residente da ILPI, que o ocupa predominantemente com ler e ouvir rádio. Com o tempo essas atividades são abandonadas em função de perdas visuais e auditivas, que precisam ser corrigidas, mas nem sempre são priorizadas (BULLA; MEDIONDO, 2004). Ademais, as instituições não possuem espaço físico planejado para lazer, principalmente as mais necessitadas (FALEIROS; JUSTO, 2007). Como citado por Pelegrin et al. (2008) o ideal para uma boa qualidade de vida do idoso institucionalizado seria o trabalho conjunto das equipes multidisciplinares, observando as diferentes necessidades dos residentes. Isso permitiria melhor desfrute do lazer, uma vez que cuidados essenciais, de saúde e conforto do espaço físico, fossem garantidos e preservados.

Para garantir uma maior diversificação das atividades de lazer nas ILPIs, variáveis como recursos financeiros do idoso, da família e da instituição podem contribuir para melhoria da qualidade destas práticas. É sabido que instituições com menos recursos tendem a disponibilizar menos esses serviços, apesar de reconhecerem a importância do lazer na qualidade de vida do residente (CREUTZBERG; GONÇALVES; SOBOTTKA, 2007). No entanto, isso não significa dizer que não é possível ofertar o lazer a baixo custo. O mais importante é que, a partir da compreensão do lazer como necessidade humana, os esforços sejam somados para o cumprimento legal desse direito a fim de garantir o bem-estar da população idosa.

Grossi, Schardosim e Vargas (2005) estudaram o lazer em idosos institucionalizados e perceberam que, para muitos, não há distinção entre ocupações e lazer. Alguns residentes denominavam lazer os serviços domésticos como atender a porta, executar pequenos consertos, auxiliar colegas doentes, ir ao banco. Outros identificaram o lazer com caminhada, dança, pintura, ouvir rádio, leitura da Bíblia e fazer palavras cruzadas. Para outros ainda, as poucas atividades às quais se interessam são limitadas por problemas de saúde, por exemplo, gostava de dançar, mas sofreu isquemia, gostava de crochê, mas agora vê pouco. 
A ILPI de cunho filantrópico experimenta uma variedade de dificuldades em termos de recursos humanos e materiais. Suas diferenças muitas vezes recaem sobre o tipo de gestão à qual são submetidas, gerando oportunidades de parcerias ou propagando o isolamento da ILPI do resto da cidade. O lazer, enquanto não for básico para o residente da ILPI, vem sendo preterido nessas instituições, muitas vezes designado como tarefa de voluntários ou estagiários do ensino superior, sem o devido preparo. Diante desse quadro, e com base na literatura científica que ampara o lazer como promotor de saúde física, psicológica e social na velhice, o objetivo deste trabalho foi investigar a atualidade das práticas de lazer de idosos independentes residentes em ILPIs filantrópicas conveniadas com a $\mathrm{PBH}$. Essas práticas de lazer referem-se àquelas que efetivamente acontecem na vida do idoso institucionalizado, na visão dele, seja por escolha pessoal, seja por oferecimento da moradia coletiva.

\section{Procedimentos metodológicos}

Este estudo possui delineamento de tipo exploratório, descritivo e transversal, contemplando uma abordagem predominantemente qualitativa, ainda que lance mão de dados quantitativos. Foi aprovado pelo Comitê de Ética em Pesquisa da Universidade Federal de Minas Gerais (COEP-UFMG) conforme Parecer nº 085/2011.

\subsection{PARTICIPANTES}

A amostra contou com 15 das 17 ILPIs filantrópicas conveniadas com a PBH e envolveu 47 idosos (33 mulheres e 14 homens), faixa etária de 62 a 94 anos, e média de 79,5 anos. O tempo de institucionalização variou de 3 meses a 17 anos. Utilizouse o critério de um mínimo de três meses de moradia na instituição, que corresponde ao tempo médio que o idoso leva para se adaptar ao local (SILVA et al., 2006). 
A escolha por ILPIs filantrópicas e conveniadas com a PBH se deu em função de poucos recursos que dispõem as ILPIs filantrópicas, necessitando de apoio do poder público para manter seu funcionamento (alimentação, cuidados essenciais e lazer). Os dados poderão indicar se poder público e instituição vem cumprindo pelo menos minimamente seu papel no quesito lazer para a promoção do bem-estar dos idosos. Por outro lado, a condição de conveniamento assegura a legalidade da parte jurídica e fiscal das ILPIs, indicando mais segurança e transparência nos serviços oferecidos nestes espaços.

Os moradores são avaliados e categorizados em grau de dependência I (independentes), grau de dependência II (dependência em até três atividades de autocuidado para a vida diária, sem comprometimento cognitivo ou com alteração cognitiva controlada) e grau de dependência III (requer assistência em todas as atividades de autocuidado da vida diária e/ou com comprometimento cognitivo), conforme classificação da Resolução da Diretoria Colegiada (RDC) n. 283/03 da ANVISA (AGÊNCIA NACIONAL DE VIGILÂNCIA SANITÁRIA, 2005). Todos os idosos do estudo são de grau I ou II, com boa capacidade cognitiva para responder à entrevista da pesquisa, ou seja, considerados independentes cognitivamente. O recurso de consulta aos prontuários médicos disponibilizados pelas ILPIs também foi utilizado a fim de verificar a condição de boa capacidade cognitiva do idoso para participação na pesquisa. Ademais, buscou-se abordar participantes em condições de escutar as perguntas sem que fosse necessário elevar o volume de voz e em condições de falar com dicção audível e compreensível para o entrevistador.

\subsection{INSTRUMENTOS}

Foi elaborado um roteiro de entrevista semiestruturada, com base na literatura científica referente a idosos institucionalizados. Esse roteiro é composto de perguntas abertas sobre experiências de lazer na vida adulta até a atualidade, especialmente no espaço institucional, procurando apreender interesses e expectativas de atividades que possam estimular vivências de lazer. Um estudo-piloto 
foi conduzido com três idosos não institucionalizados, com faixa etária acima de 75 anos, avaliando se as perguntas da entrevista eram compreensíveis.

\subsection{Procedimentos de coleta de dados}

A entrevista foi gravada com permissão do participante, precedida da apresentação do Termo de Consentimento Livre e Esclarecido (TCLE). O agendamento das entrevistas foi conforme a disponibilidade de horários da ILPI e do participante. Solicitou-se à instituição uma sala que garantisse privacidade, com conforto e sem interrupções.

\subsection{Procedimentos de ANÁlise dos dados}

As entrevistas transcritas foram submetidas à análise de conteúdo com inspiração nos procedimentos sugeridos por Bardin (2009). Essa técnica possibilita captar conteúdos sobre o problema investigado. Foram identificadas semelhanças temáticas nas respostas dos participantes, reunidas em agrupamentos temáticos, originando categorias de respostas. Todos os dados foram analisados separadamente por duas avaliadoras, especialistas da área temática e pesquisadoras do estudo, e a seguir estes dados foram comparados. Dúvidas foram dissolvidas com um terceiro avaliador. Obteve-se a frequência de respostas em cada categoria, e os resultados foram interpretados com base na literatura.

\section{RESUltados}

O Quadro 1 mostra as categorias de respostas das práticas de lazer realizadas no espaço físico das ILPIs, a frequência de respostas por categoria e a descrição da mesma, quando pertinente. Foram contabilizadas as respostas de homens e de mulheres, embora não constem nos quadros; dados relevantes de diferença de gênero são comentados. Não constam no Quadro 1 as seguintes categorias e suas frequências de respostas, porque apresentam poucas unidades temáticas: "desenho" (4 respostas), "oficinas" (4), "jogos cognitivos" 
(4), "outras práticas" (4), e "outras respostas" (12). Quanto à categoria "outras respostas", as mesmas não são citadas posto que são respostas descontextualizadas das perguntas, ou sem referência a qualquer prática de lazer.

Quadro 1 - Frequência de respostas nas práticas de lazer dos idosos dentro da ILPI

\begin{tabular}{|c|c|c|}
\hline Prática de lazer & $\mathrm{f}$ & descrição \\
\hline Práticas religiosas & 19 & $\begin{array}{l}\text { rezar, ir à missa, grupo de oração, ajudar no } \\
\text { culto/festas religiosas }\end{array}$ \\
\hline Relações interpessoais & 18 & $\begin{array}{l}\text { fazer amizade, conversar, confraternizações, hora do } \\
\text { lanche, separar brigas de idosas }\end{array}$ \\
\hline Ginástica & 18 & - \\
\hline Assistir TV & 16 & - \\
\hline Práticas manuais/artesanais & 15 & $\begin{array}{l}\text { costurar, pintura, tapete, crochê, bordado, tricô, ponto- } \\
\text { cruz, bijuterias, fuxico, almofadas }\end{array}$ \\
\hline Festas/comemorações & 13 & $\begin{array}{l}\text { festas da ILPI, festa junina, natalina, de família, de } \\
\text { aniversário, carnaval, dia das mães }\end{array}$ \\
\hline Leitura & 11 & ler, folhear revistas \\
\hline Cuidados domésticos & 11 & $\begin{array}{l}\text { cuidar do jardim/plantas, ajudar na cozinha, arrumar } \\
\text { quarto, cuidarda capela }\end{array}$ \\
\hline Prátic as educacionais & 11 & estudar, escrever, assistir palestras, aula de EJA \\
\hline Bingo & 10 & - \\
\hline Dança & 10 & - \\
\hline Prátic as recreativas & 10 & $\begin{array}{l}\text { recreação com escolas/voluntários, gincana, cine- } \\
\text { pipoca, brincadeiras }\end{array}$ \\
\hline Prátic as musicais & 10 & cantar, tocar instrumento, assistir musicistas \\
\hline Exercício aeróbico rítmico & 9 & caminhada, bicicleta ergométrica \\
\hline Ouvir rádio & 7 & - \\
\hline Cuidados com saúde & 7 & ir na fisioterapia, cuidar da saúde \\
\hline Ajudar outros residentes & 6 & - \\
\hline Descansar & 6 & - \\
\hline Baile & 6 & ir a bailes, forró \\
\hline
\end{tabular}

Fonte: Pesquisa das autoras.

Movimento, Porto Alegre, v. 19, n. 04, p. 69-93, out/dez de 2013. 
O Quadro 1 mostra que práticas religiosas, relações interpessoais, ginástica, assistir TV e práticas manuais/artesanais envolvem as práticas de lazer mais citadas pelos 47 idosos institucionalizados entrevistados. De início, é possível afirmar, tanto em termos quantitativos quanto qualitativos, ao se contemplar o quadro como um todo, que há oferta de lazer nestas instituições filantrópicas conveniadas com a $\mathrm{PBH}$, embora esta oferta varie de ILPI para ILPI.

Outra situação a considerar sobre as categorias criadas é a semelhança apresentada por algumas delas em sua essência. Embora muitas delas possam ser similares como "ginástica" e "exercício aeróbico rítmico", as mesmas foram separadas pela diferenciação na forma de organização. Enquanto a prática "ginástica" envolve sempre um grupo de orientadores disponibilizados pelo Poder Público Municipal, o exercício aeróbico rítmico, como caminhada e bicicleta ergométrica, nem sempre envolve um orientador.

É importante comentar a categoria "relações interpessoais", dado que não engendra uma prática de lazer que envolva alguma atividade explícita. Nessa categoria constam as respostas que valorizavam as interações sociais significativas, destacadas como momentos de lazer pelo caráter de diversão e de desprendimento que proporcionam aos entrevistados. A unidade temática "separar brigas" (discussões) ressalta, inclusive, a intensidade do envolvimento nessas relações entre residentes, evidenciando seu valor para o(a) entrevistado(a).

Enquanto homens entrevistados se dedicam mais a práticas educacionais, leitura, oficinas e exercício aeróbico rítmico, as mulheres se dedicam a cuidados domésticos, práticas musicais e bingo, mesmo na ILPI. O jogo de bingo indica pouca participação masculina, mas as oficinas que se assemelham a práticas de lazer de outros momentos da vida (como oficinas de reciclagem, jardinagem, teatro) parecem despertar maior interesse nestes homens. Embora as atividades ofertadas pelas ILPIs não façam distinção de gênero para a 
participação nestas práticas, percebe-se esta segregação pela demanda dos próprios idosos no ambiente institucional das ILPIs analisadas.

O Quadro 2 mostra as categorias de respostas das práticas de lazer realizadas fora do espaço físico da ILPI, a frequência de respostas por categoria e a descrição da mesma, quando pertinente. As práticas mais frequentadas são aquelas ofertadas pela própria ILPI, com apoio do voluntariado.

Quadro 2 - Frequência de respostas nas práticas de lazer dos idosos realizadas fora da ILPI

\begin{tabular}{c|c|l}
\hline Prática de lazer & f & \multicolumn{1}{|c}{ descrição } \\
\hline Passeios ofertados pela ILPI & 17 & Passeios diversos oferecidos pela ILPI \\
\hline Interações com família & 14 & Visitar familiares, festas e passeios em família \\
\hline Centros de convivência & 8 & $\begin{array}{l}\text { Ir ao centro de convivência da PBH ou da ONG do } \\
\text { bairro, ginástica no posto de saúde, EJA }\end{array}$ \\
\hline Passeios & 5 & Visitar ou passear com amigos \\
\hline Outras práticas & 7 & Fazer compras, ir a apresentações culturais \\
\hline
\end{tabular}

Fonte: Pesquisa das autoras.

As práticas de lazer externas aos domínios da ILPI são claramente menos diversificadas e menos frequentes em função das dificuldades de logística. Não se trata tão somente de uma questão de transporte adequado aos residentes e de acompanhantes nos passeios. Outra questão que se apresenta é a adequação dos espaços de lazer para receber os idosos. Muitos lugares, como parques e praças, não possuem rampas de acesso ou corrimãos. Alguns trajetos têm calçamento irregular, buracos e desníveis. Essas observações são todas calcadas no que foi visto nas ILPIs visitadas para o estudo. Estas questões, portanto, atravessam as oportunidades de oferta de práticas de lazer externas às ILPIs. Por essas razões as práticas de lazer externas à ILPI geralmente envolvem uma pequena parcela 
de idosos, sendo esse um dos motivos por que são descritas separadamente. $\mathrm{O}$ depoimento de coordenadores entrevistados nas ILPIs corroboram estas afirmativas, ao citar que em passeios os cadeirantes na maioria das vezes são excluídos pela indisponibilidade de transporte. Os dados sobre os coordenadores serão tema de outro estudo em fase de publicação.

Interessante notar que a segunda categoria com maior frequência de respostas nas práticas de lazer fora da ILPI também envolve relacionamentos, nesse caso, familiares. Assim, os passeios não organizados pela ILPI também destacam esses relacionamentos.

\section{Discussão}

A visualização das categorias de respostas e dos exemplos nas descrições fornecidas demonstra inicialmente uma heterogeneidade de práticas de lazer dos participantes, advindas em sua maioria das experiências de vida prévias à institucionalização. McPherson (2000) argumenta nessa direção, relacionando estilo de vida, grupos sociais e lazer.

No entanto, Davim et al. (2004), Lopes et al. (2007), Maia et al. (2008), Pavan, Meneghel e Junges (2008) e Gobbi et al. (2008) contrariam essa heterogeneidade de práticas de lazer do idoso em ILPIs, salientando a falta de opção enfrentada pelos residentes. O presente estudo descreve as práticas atuais de idosos na instituição e, de modo geral, mostra um quadro mais positivo. Obviamente há peculiaridades de cada instituição, como comentado, calcadas em diferenças de gestão e recursos. Outro aspecto é que o trabalho tratou de ILPIs filantrópicas conveniadas com a PBH e que, portanto, tem respaldo e acompanhamento do poder público.

As práticas de lazer citadas pelos moradores indicam maior quantidade de atividades do que em etapas anteriores de vida. Esta afirmação é sustentada em outras fases da presente pesquisa ao questionarmos os idosos sobre as experiências de lazer a partir da aposentadoria, dados a serem publicados em outro estudo. Porém, 
nem sempre as atividades ofertadas são suficientes para promover qualidade de vida. Dois idosos informaram que a instituição oferece muitas atividades, mas que o interesse é pequeno. Esse dado está mais próximo daqueles encontrados na literatura sobre lazer em ILPIs no que diz respeito não apenas à oferta, mas à adesão às práticas.

Dentro do espaço institucional destacaram-se práticas religiosas e relações interpessoais. As práticas religiosas na ILPI tem como ponto central a oração e leituras religiosas, muitas vezes motivadas pela diminuição da mobilidade física e empecilhos no deslocamento pela cidade (GOLDSTEIN; NERI, 2007). Alguns aspectos específicos reforçam tais atividades, como nos casos em que a residência coletiva pertence a alguma ordem religiosa. Por outro lado, é fato que as ILPIs asseguram aos idosos a liberdade de crença, como previsto no Estatuto do Idoso.

Há estudos que evidenciam o bem-estar dos indivíduos que exercem práticas religiosas - um dos componentes para avaliar o estado de saúde do idoso (DUARTE; LEBRÃO; LAURENTI, 2008). A religiosidade oferece aos idosos uma base emocional para lidar com medos e perdas, motivando-os a encontrar significado à vida (ALVES, 2006). Além dos ganhos emocionais e sociais, Hill et al. (2006 apud RIBEIRO; YASSUDA, 2007) demonstraram que há redução na velocidade das perdas cognitivas em idosos com participação regular em práticas religiosas.

No ambiente institucional, o trabalho contínuo de voluntários de congregações religiosas ou grupos de cultos ecumênicos incentivam a participação de todos os residentes. Na percepção dos idosos, os encontros fortalecem vínculos de amizade, senso de comunidade e altruísmo. Outros mencionam sentirem-se valorizados por contribuir com pequenas tarefas na manutenção dos espaços de oração e pela oportunidade de encontrar colegas mais próximos para orações especiais.

$\mathrm{Na}$ categoria relações interpessoais os participantes admitem vontade de se relacionar com outros residentes ou voluntários e fazer amizades. Por ser gregário, o ser humano tem necessidade de contato 
um com o outro. É na possibilidade de maior aproximação, intimidade e proximidade que vão se formar vínculos. Aqualidade destas relações pode contribuir para o bem-estar, felicidade e capacidade de interação (HERÉDIA; CORTELLETTI; CASARA, 2004). A unidade temática que mais contribuiu para a construção da categoria foi "bater papo com outros residentes" (citada por 10 pessoas). Poder-se-ia argumentar que a categoria relações interpessoais destoa das demais, pois não envolve uma prática, como ginástica, artes manuais e artesanais, etc. Contudo, as respostas dos idosos salientaram o caráter da interação social por si só, com ênfase para a conversa descontraída, como no caso do bate-papo.

Ainda assim, há oportunidades para se relacionar que não são bem percebidas pelos idosos em determinadas situações nas ILPIs. De acordo com Moragas (1997), as refeições representam um dos momentos mais oportunos para as relações sociais dentro das ILPIs, mas são pouco aproveitadas pelos residentes, como observou o entrevistado E45: "Comem de repente, comem depressa. Não tem lugar nenhum pra ir, sabe. Ficam ansiosos". Atividades que estimulem boas interações são necessárias, mas exigem atuação interdisciplinar. $\mathrm{Na}$ experiência profissional, muitos idosos institucionalizados apresentam dificuldades, apesar de manifestar que gostariam de fazer amizades. Também a experiência de estagiários de psicologia na observação das refeições coletivas nos refeitórios de ILPIs de Belo Horizonte relata a quase ausência de interação nesse momento conjunto, corroborando Moragas (1997).

Atividades como ginástica e caminhada são também bastante frequentadas pelos idosos. Predominaram participantes do sexo feminino possivelmente pela maior conscientização quanto a cuidados com a saúde, senso de autocuidado, aspectos culturais e menos problemas físico-musculares. Um fator que contribui para o maior número de participantes nas práticas de lazer é a regularidade de oferta. Herédia; Cortelletti e Casara (2004) perceberam que idosos institucionalizados citam a caminhada somente porque a casa a oferece regularmente. 
Outras práticas que envolvem mobilidade física, tais como dança, baile e práticas recreativas, são dependentes de serviço voluntariado ou da própria ILPI e tem frequência variável. Em seis ILPIs os bailes oferecidos mensalmente por voluntários despertam a atenção até mesmo de quem pouco participa de práticas recreativas ou de outras formas de lazer na ILPI. No caso do baile, o grupo consiste de profissionais da música e dança que objetivam integrar os residentes. São convidados todos os idosos (cadeirantes ou não) para diferentes formas de participação (cantando, dançando, batendo palmas, assistindo). Para Moraes e Salvajolli (2007), bailes e música na ILPI estimulam o relacionamento interpessoal e reduzem ansiedade. Ademais, para aqueles com impedimento físico, o baile, dança ou recreação com movimentação física oportunizam relações interpessoais e vivência de emoções positivas.

A categoria festas/comemorações representa espaços potenciais para estimular sociabilidade e vivências de lazer compartilhado. As festas de Natal são descritas como animadas em virtude das visitas e presentes, mas não envolvem os residentes na organização do evento. Alguns estudos descreveram essa participação na festa como prática positiva para os moradores (MORAES; SALVAJOLLI, 2006; GRAEFF, 2005).

Assistir TV foi uma prática de lazer bastante citada. Em metade das ILPIs há TV no quarto, com liberdade de escolher programas. $\mathrm{Na}$ entrevista esses idosos se mostraram mais seletivos em relação às programações, como também denotado por Acosta-Orjuela (2001). Os cadeirantes admitiram ocupar a maior parte do tempo assistindo TV. Para Acosta-Orjuela (2001) e Polaro (2001), ambientes pouco favoráveis à socialização induzem à maior utilização da TV. Além disso, o avanço etário e o tempo de institucionalização influenciam essa prática até mesmo em idosos mais críticos (ACOSTA-ORJUELA, 2001). De todo modo, há o caso de uma idosa que recebe, em seu quarto, outras residentes que não possuem TV para assistirem a novela. Ainda assim, Groenwald (2004) destaca que o uso excessivo de rádio e de TV nas ILPIs aumentam a ociosidade e o isolamento social. 
Leitura e práticas educacionais foram mais apontadas por homens. Um dos motivos prováveis é a maior escolarização do sexo masculino (HERÉDIA, CORTELLETTI, CASARA, 2004) no grupo etário estudado. Quanto ao tipo de leitura, os homens preferem jornais, enquanto as mulheres preferem textos religiosos. Porém, déficits visuais reduzem o número de participantes nas práticas educacionais e na leitura. Há idosos que aguardam tratamento ou carecem de recurso para a aquisição de óculos.

Oliveira, Cruvinel e Angeli (2007) indicaram que o hábito de leitura contribui para a diminuição dos lapsos de memória e déficits de atenção. Além disso, leituras prazerosas podem despertar reflexões que estimulem o bem-estar subjetivo, como ilustra a fala de E45: "Um tempo atrás eu li um livro falando que os amigos são os irmãos que a vida nos permite escolher. Então eu tenho muitos amigos que são verdadeiros irmãos para mim".

O jogo de bingo foi indicado por 10 participantes idosos, todos mulheres. Supostamente esta prática é mais frequente pela grande quantidade de voluntários e estagiários que oferecem esse jogo. $\mathrm{Na}$ descrição dos próprios idosos, o jogo é acompanhado de brindes e presentes. Moraes e Salvajolli (2006) se referem ao bingo como um jogo simples que diverte e socializa os independentes e os fragilizados, com apoio de cuidadores. Bem aceito pelos idosos em uma ILPI não filantrópica no Rio de Janeiro, segundo as autoras citadas, outros estudos também identificaram o bingo como atividade comum nas ILPIs (FALEIROS; MORANO, 2009; FREITAS, 2010; LOPES et al., 2007).

Os idosos admitiram satisfação e espontaneidade na participação de cuidados domésticos, pois se veem colaborando com algo para a ILPI. Herédia; Cortelletti e Casara (2004) mencionam que, diferente dos idosos que residem em domicílio próprio, os institucionalizados usam estas práticas para ocupar o tempo. Ao se depararem com a proibição de trabalho nas ILPIs, perdem controle sobre seu cotidiano, sentindo-se inúteis, como afirma o entrevistado E5: "Ocês aposentou, num pode trabalhar mais... Tamo aí parada, né!" O estudo do Instituto Paranaense de Desenvolvimento 
Econômico e Social (2008) sobre a ocupação de idosos em 229 ILPIs no estado do Paraná demonstrou que a vontade da maioria dos moradores era ocupar-se com atividade doméstica.

Fora da ILPI, os passeios ofertados pela casa são bem aproveitados, mas são de baixa frequência pela precariedade de transporte e falta de acompanhantes. Outra constatação é que, quanto maior o número de idosos dependentes, menor é a frequência de passeios externos, pelas mesmas dificuldades.

As interações com familiares nos passeios estão associadas ao interesse entre as partes para compartilhar momentos de lazer. Para Zingoni (2008) o tempo de lazer em casa fortalece as relações familiares. Parker (1978), ao estudar lazer e família, relata as possibilidades de descanso que o lar propicia aos seus membros, assim como momentos de sociabilidade e prática de hobbies.

A interação do residente com a sua família fora da instituição depende, em certa medida, da relação estabelecida entre instituição e família. $\mathrm{O}$ contato frequente, atualizado e proveitoso entre as partes pode fomentar a interação do residente com seus familiares fora das dependências da moradia coletiva. Isso pode ocorrer tanto na forma de telefonemas para a família, lembrando-as de buscar o residente para passeios, como tendo um dia ao mês no qual a família se comprometa a buscar o idoso para sair. Ainda raramente mencionada, todavia, é a experiência de acompanhantes designados especialmente para estar junto ao residente em seus passeios fora da instituição, seja para ir ao encontro da família ou dirigir-se a outros locais da cidade.

4.1 IMPLICAÇÕES PARA O PROFISSIONAL QUE SE DESTINA A PROPORCIONAR PRÁTICAS DE LAZER NA ILPI

O estudo conduzido pretende agregar à literatura disponível sobre lazer para idosos no Brasil no que diz respeito à situação de institucionalização filantrópica. As ILPIs desse contexto são, como mencionado, de natureza variada e dependem bastante da colaboração de voluntários e de convênios, por exemplo, com o poder 
público, como no caso da $\mathrm{PBH}$, e com instituições de ensino superior, que ofertam atividades de estágio em cursos de ensino superior. Estas parcerias contribuem para a oferta de práticas de lazer aos residentes.

Ao profissional que pretende trabalhar vivências de lazer nas ILPIs, especialmente naquelas com recursos limitados, cabem considerações que podem contribuir tanto para a diversificação da oferta das práticas, como para o aumento e fortalecimento da adesão dos moradores a elas. O presente trabalho, ainda que predominantemente exploratório e descritivo, tem a intenção de fornecer recomendações nesse sentido para que a pesquisa possa alcançar a prática profissional contextualizada.

Primeiramente é necessário conhecer o público ao qual se destinarão as práticas de lazer. Assim, cabe ao profissional entender que se trata de pessoas com características, necessidades e impedimentos específicos da velhice. Estão em situação de institucionalização, o que interfere na liberdade individual mediante as normas de funcionamento da ILPI no uso de espaços e cumprimento de horários. O profissional de lazer deve conhecer em profundidade os residentes, privilegiando a escuta sobre cada história de vida, observando-os na interação com colegas e nas atividades da residência, conhecendo a equipe de trabalhadores da ILPI, trocando informações com a direção/coordenação, e conhecendo as diretrizes que amparam a instituição.

Importante será o constante diálogo e boa parceria com os voluntários que atuam na instituição, não os considerando concorrentes na oferta de lazer, mas aliados em potencial. Estas pessoas, ainda que ofereçam práticas com frequência variável e recursos escassos, possuem conhecimento privilegiado acerca de cada idoso participante. O diálogo igualitário com estes voluntários, que muitas vezes tem pouco conhecimento profissional e científico sobre o que estão propondo, confirmará seu valor como atores relevantes no contexto de poucos recursos que as ILPIs dispõem para investir em questões para além dos cuidados básicos. 
Obviamente, e como o presente trabalho salienta a priori, cabe conhecer os interesses de lazer dos residentes, mesmo que façam referência a práticas que não estão mais a seu alcance. É exemplo desta situação o caso em que o idoso foi exímio colecionador de modelos de aviões em miniatura para montar, mas que teve que abrir mão do hobby por dificuldades de mobilidade nas mãos. Este sujeito possui, no entanto, um conhecimento vivenciado sobre o qual pode falar, compartilhando seus conhecimentos, desde que o contexto apropriado seja oferecido para tal. Assim, como neste exemplo, o profissional de lazer pode proporcionar tais oportunidades, fazendo com que os residentes conheçam mais sobre a história de vida uns dos outros, mas também que compartilhem experiências e se vejam valorizados como dotados de conhecimento específico.

Com base nas entrevistas realizadas com coordenadores das ILPIs que também integram a pesquisa, na atuação profissional da pesquisadora em instituições asilares, nas entrevistas com idosos deste trabalho e na literatura encontrada, foram elaboradas as seguintes orientações para ILPIs:

a) organizar reuniões e encontros entre os profissionais que oferecem práticas de lazer/recreação na ILPI (voluntariado, estagiários, parcerias, funcionários) para troca de experiências e discussão da realidade dos idosos;

b) estruturar juntamente com os profissionais que oferecem o lazer na ILPI um cronograma anual de atividades;

c) estimular a prática de jogos cognitivos, ao menos uma vez por semana;

d) como exemplificado por uma ILPI participante do estudo, criar o "Conselho": reunião com idosos conduzida por um profissional treinado, para discutir propostas de práticas de lazer e assuntos pertinentes à instituição;

e) como exemplificado por uma ILPI envolvida no estudo, incluir nas comemorações o "Dia do Voluntariado"; 
f) visitar outras ILPIs que promovem o lazer para troca de experiências;

g) incluir nas comemorações a participação de outras ILPIs.

As recomendações realizadas não esgotam as possibilidades que podem advir de futuros estudos e de novas experiências profissionais com o lazer nas ILPIs. No entanto, são caminhos que podem ser experimentados e transformados, sempre com o intuito de proporcionar ao morador da ILPI a vivência de uma dimensão tão cara à qualidade de vida e à felicidade dos seres humanos: o lazer.

\subsection{CONSIDERAÇÕES FINAIS}

A ampliação da adesão dos idosos em práticas de lazer ofertadas na ILPI dependerá de um trabalho interdisciplinar, visando a educabilidade dos residentes para melhoria na qualidade das relações. Oferecer diversas atividades não é condição única para envolver participantes, mas sim o empenho que favoreça suporte às interações entre residentes.

Entende-se que a educabilidade se aproxima da educação para o lazer que, no entender de Marcellino (1996), refere-se à compreensão do significado do lazer e de sua valorização para o alcance da autonomia. Para tanto, esse processo educacional deverá envolver o contato com atividades que atendam diferentes interesses a fim de permitir às pessoas exercitar a livre escolha e serem ativas nesse processo.

Espera-se que o presente trabalho tenha não apenas se tornado mais um estudo na literatura acerca do lazer em idosos no Brasil, mas que tenha oferecido insights para o profissional que trabalha o lazer com esta faixa etária, bem como para o pesquisador que se dedica à integração desses temas no contexto científico. Para além de tão somente sugerir que mais estudos sejam conduzidos, acreditase que estudos que avaliem a satisfação com o envolvimento nas práticas de lazer ofertadas nas ILPIs, identificando a frequência da participação, a intensidade da participação, a abrangência das 
interações sociais nessa participação e o impacto da prática de lazer para o bem-estar subjetivo do residente possam dar um passo adiante na produção científica nacional na tríade lazer-idoso-ILPI. 
Leisure practices in institutionalized elderly

Abstract: This study describes the experiences of leisure practices in elderly residents of philanthropic long term collective residential homes with formal partnership with Belo Horizonte City Hall, Brazil. It is a predominantly qualitative research that belongs to the interdisciplinary field of leisure studies. Forty-seven elderly citizens were interviewed ( $70 \%$ women), with mean age of 80 years-old. The most cited leisure practices were religious, interpersonal relationships, gymnastics, watching TV and handicraft practices. Results are discussed based on literature and recommendations are offered to the ones that intend to promote leisure experiences in long term collective residential homes for the elderly.

Keywords: Leisure activities. Elderly. Residential homes for the elderly.

\section{Prácticas de ocio en ancianos instituciona- lizados \\ Resumen: El estudio relata las experiencias de las prácticas de ocio en los ancianos residentes en instituciones filantrópicas de larga estancia en convenio con la Municipalidad de Belo Horizonte. Se trata de una investigación predominantemente cualitativa que se inscribe en el campo interdisciplinario de los estudios del ocio. Se entrevistaron 47 ancianos ( $70 \%$ mujeres) con una edad alrededor de 80 años. Las prácticas más citadas fueron religiosas, relaciones interpersonales, gimnasia, mirar la televisión, manualidades y artesanía. Los resultados se discuten con base en la literatura y se trazan recomendaciones para profesionales que quieran promover el ocio para ancianos institucionalizados.}

Palabras clave: Actividades recreativas. Ancianos. Ancianatos. 


\section{REFERÊNCIAS}

ACOSTA-ORJUELA, Guilhermo Maurício. Como e porque idosos brasileiros usam a televisão: um estudo dos usos e gratificações associados ao meio. 2001. 169 f. Tese (Doutorado em Educação) - Universidade Estadual de Campinas, Campinas, 2001.

AGÊNCIA NACIONAL DE VIGILÂNCIA SANITÁRIA. Resolução n. 283, de 26 de setembro de 2005. Aprova o Regulamento Técnico que define normas de funcionamento para as Instituições de Longa Permanência para idosos, de caráter residencial. Diário Oficial da União, Brasília, 27 set. 2006. Disponível em: <http:// portal.saude.al.gov.br/suvisa/files/rde 283pdf.>. Acesso em: 6 dez. 2010.

AGICH, George. Dependência e autonomia na velhice: um modelo ético para o cuidado de longo prazo. São Paulo: Loyola/Centro Universitário São Camilo, 2008.

ALVES, Vicente Paulo. A religião e os idosos. In: FALEIROS, Vicente de Paula; LOUREIRO, Altair Macedo Lahud (Org.). Desafios do envelhecimento: vez, sentido e voz. Brasília: Universa, 2006. p. 45-55.

AQUINO, Cássio Adriano Braz; MARTINS, José Clerton Oliveira de. Ócio, lazer e tempo livre na sociedade do consumo e do trabalho. Mal Estar e Subjetividade, Fortaleza, v. 7, n. 2, p. 479-500, set. 2007.

BARDIN, Laurence. Análise de conteúdo. 4. ed. Lisboa: Edições 70 LDA, 2009.

BULLA, Leonia Capaverde; MEDIONDO, Marisa Zazzeta de. Velhice, dependência e vida cotidiana institucional. In: CORTELLETTI, Ivonne A.; CASARA, Míriam Bonho; HERÉDIA, Vânia Beatriz Merlotti (Org.). Idoso asilado: um estudo gerontológico. Caxias do Sul: Educs/Edipucrs, 2004. p. 87-113.

CAMARANO, Ana Amélia; KANSO, Solange. As instituições de longa permanência para idosos no Brasil. Revista Brasileira de Estudos Populacionais, Rio de Janeiro, v. 27, n. 1, p. 233-235, jan./jun. 2010.

CREUTZBERG, Marion; GONÇALVES, Lúcia Hisako Takase; SOBOTTKA, Emil Albert. A sobrevivência econômica de instituições de longa permanência para idosos empobrecidos. Revista Latino Americana de Enfermagem, Ribeirão Preto, v. 15, n. 5, p. 748-754, set./out. 2007.

D'ALENCAR, Raimunda Silva; CAMPOS, Juliana Britto. Velhice e trabalho: a informalidade como (re) aproveitamento do descartado. Estudos Interdisciplinares sobre o Envelhecimento, Porto Alegre, v. 10, p. 29-43, 2006.

DAVIM, Rejane Mare Barbosa et al. Estudo com idosos de instituições asilares no município de Natal/RN: características sócio-econômicas e de saúde. Revista Latino Americana de Enfermagem, São Paulo, v. 12, n. 3, p. 518-524, maio/jun. 2004. 
DOLL, Johannes. Educação, cultura e lazer: perspectivas de velhice bem sucedida. In: NERI, Anita Liberalesso (Org.). Idosos no Brasil: vivências, desafios e expectativas na terceira idade. São Paulo: Perseu Abramo/Edições SESC-SP, 2007. p. $109-123$.

DUARTE, Yeda Aparecida Oliveira de; LEBRÃO, Maria Lúcia; LAURENTI, Rui. Religiosidade e envelhecimento: uma análise do perfil de idosos do município de São Paulo. Saúde Coletiva, São Paulo, v. 5, n. 24, p. 173-177, 2008.

FALEIROS, Nayara Paula; JUSTO, José Sterza. O idoso asilado: a subjetividade intramuros. Revista Brasileira de Geriatria e Gerontologia, Rio de Janeiro, v. 10, n. 3, p. 327-337, 2007.

FALEIROS, Vicente Paula de; MORANO, Tereza. Cotidiano e relações de poder numa instituição de longa permanência para pessoas idosas. Revista Textos \& Contextos, Porto Alegre, v. 8, n. 2, p.319-338, jul./dez. 2009.

FERRARI, Maria Auxiliadora Cursino. Lazer, ocupação do tempo livre e os programas da terceira idade. In: NETTO, Matheus Papaleo. Tratado de gerontologia. São Paulo: Atheneu, 2007. p. 243-251.

FREITAS, Denise Cuoghi de Carvalho Veríssimo. Vulnerabilidade e resiliência em idosos institucionalizados. Revista Kairós, São Paulo, p. 63-74, jun. 2010.

GOBBI, Sebastião et al. Comportamento e barreiras: atividade física em idosos institucionalizados. Psicologia: Teoria e Pesquisa, Brasília, v. 24, n. 4, p. 451-458, 2008.

GOLDSTEIN, Lucila Lucchino; NERI, Anita Liberalesso. Tudo bem graças a Deus: religiosidade e satisfação na maturidade e na velhice. In: NERI, Anita Liberalesso (Org.). Qualidade de vida e idade madura. 7. ed. Campinas: Papirus, 2007. p. 109-136.

GOMES, Christianne Luce. Significados de recreação e lazer: reflexões a partir da análise de experiências institucionais. 2003. 322 f. Tese (Doutorado em Educação) - Universidade Federal de Minas Gerais, Belo Horizonte, 2003.

GOMES, Christianne Luce. (Org.). Dicionário crítico do lazer. Belo Horizonte: Autêntica, 2004.

GRAEFF, Lucas. O "mundo da velhice" e a cultura asilar: estudo antropológico sobre memória social e cotidiano de velhos no Asilo Padre Cacique em Porto Alegre. 2005. 172 f. Dissertação (Mestrado em Antropologia Social) - Universidade Federal do Rio Grande do Sul, Porto Alegre, 2005.

GROENWALD, Rosa. Idosos asilados no município de Canoas. In: CORTELLETTI, Ivonne A.; CASARA, Míriam Bonho; HERÉDIA, Vània Beatriz Merlotti (Org.). Idoso asilado: um estudo gerontológico. Caxias do Sul: Educs/Edipucrs, 2004. p. 13-60. 
GROSSI, Patrícia Krieger; SCHARDOSIM, Mareli.; VARGAS, Cristina Oliveira Lopes. Idosos institucionalizados. In: DORNELLES, Beatriz; COSTA, Gilberto José Corrêa da (Org.). Lazer, realização do ser humano: uma abordagem para além dos 60 anos. Porto Alegre: Sagra Luzzato, 2005. p. 136-143.

HERÉDIA, Vânia Beatriz Merlotti; CORTELLETTI, Ivonne A.; CASARA, Miriam Bonho. Institucionalização do idoso: identidade e realidade. In: CORTELLETTI, Ivonne A.; CASARA, Miriam Bonho; HERÉDIA, Vânia Beatriz Merlotti (Org.). Idoso asilado: um estudo gerontológico. Caxias do Sul: Educs/Edipucrs, 2004. p. 13-60.

INSTITUTO PARANAENSE DE DESENVOLVIMENTO ECONÔMICO E SOCIAL. Instituições de longa permanência para idosos: caracterização e condições de atendimento. Curitiba, 2008. Disponível em: <www.ipardes.gov.br>. Acesso em: 16 nov. 2011.

LOPES, Fernanda Luca et al. Diagnósticos de enfermagem de idosos residentes em uma instituição de longa permanência (ILP). Revista Ciência, Cuidado e Saúde, Maringá, v. 6, n. 1, p. 59-67, jan./mar. 2007.

MAIA, Gabriela Falten; LONDERO, Susane; HENZ, Alexandre Oliveira de. Velhice, instituição e subjetividade. Interface-Comunicação, Saúde, Educação, v. 12, n. 24, p. 49-59, 2008.

MARCELLINO, Nelson Carvalho. Estudos do lazer: uma introdução. 2. ed. Campinas: Autores Associados, 1996.

MCPHERSON, Barry. Envelhecimento populacional e lazer. In: SESC/WRLA (Org.). Lazer numa sociedade globalizada. São Paulo: SESC, 2000. p. 227-249.

MORAES, Eliane Medeiros de; SALVAJOLLI, Jussara Anderson Mendes. Recreação e lazer em uma instituição de longa permanência para idosos. In: PINTO, Sílvia Patrícia Lima de et al. (Org.). O desafio multidisciplinar: um modelo de instituição de longa permanência para idosos. São Caetano do Sul: Yendis, 2006. p. 369-379.

MORAGAS, Ricardo Moragas. Gerontologia social: envelhecimento e qualidade de vida. São Paulo: Paulinas, 1997.

OLIVEIRA, Kátia Luciane de; CRUVINEL, Mirian; ANGELI, Acácia Aparecida Santos. Atitudes de leitura e desesperança em idosos. Paidéia, Ribeirão Preto, v. 17, n. 37, p. 245-254, maio/ago. 2007.

PARKER, Stanley. A sociologia do lazer. Rio de Janeiro: Zahar, 1978.

PAVAN, Fábio José; MENEGHEL, Stela Nazareth; JUNGES, José Roque. Mulheres idosas enfrentando a institucionalização. Cadernos de Saúde Pública, Rio de Janeiro, v. 24, n. 9, p. 2187-2190, set. 2008. 
PELEGRIN, Andressa Karina Amaral Plá et al. Idosos de uma instituição de longa permanência de Ribeirão Preto: níveis de capacidade funcional. Arquivos de Ciências da Saúde, São José do Rio Preto, v. 15, n. 4, p.182-188, out./dez. 2008.

POLARO, Sandra Helena Isse. A satisfação do usuário idoso: um indicador de qualidade do cuidado à saúde. 2001. 110 f. Dissertação (Mestrado em Saúde Pública) - Universidade Federal do Pará, Belém, 2001.

RIBEIRO, Pricila Cristina Correa; YASSUDA, Mônica Sanches. Cognição, estilo de vida e qualidade de vida na velhice. In: NERI, Anita Liberalesso (Org.). Qualidade de vida na velhice: um enfoque multidisciplinar. Campinas: Alínea, 2007. p. 189204.

RODRIGUES, Minéia Carvalho. O lazer do idoso: barreiras a superar. Revista Brasileira de Ciências do Movimento, Brasília, v. 10, n. 4, p. 105-108, out. 2002.

SILVA, Cátia Andrade et al. Relacionamento de amizade na instituição asilar. Revista Gaúcha de Enfermagem, Porto Alegre, v. 27, n. 2, p. 274-283, jun. 2006.

SOARES, Dulce Helena Penna et al. Aposenta-ação: programa de preparação para a aposentadoria. Estudos Interdisciplinares sobre o Envelhecimento, Porto Alegre, v. 12, p. 143-161, 2007.

ZINGONI, Patrícia. O lugar da família nas políticas de lazer. In: MARCELLINO, Nelson. (Org.). Lazer e sociedade: múltiplas relações. Campinas: Alínea, 2008. p. 83103.

Este trabalho apresenta dados inéditos da dissertação de mestrado da primeira autora, sob orientação da segunda autora. Apoio: PPG-Estudos do Lazer da UFMG; CAPES. Agradecimentos: D. C. Silveira, M. G. A. Tirado e S. A. Carlos.

Endereço para correspondência:

Universidade Federal de Minas Gerais, EEFFTO -

Programa de Pós-Graduação em Estudos do Lazer,

Av. Antônio Carlos, 6627, Campus Pampulha, cep.31.270-901,

Belo Horizonte, Minas Gerais.

Fone: (31)3409-2303.

Recebido em: 03.12.2012

Aprovado em:11.05.2013 